\title{
Some remarks on the comparative experiment as a method in assessing populist political communication in Europe*
}

Dominika Kasprowicz

ORCID: 0000-0001-7421-2952

JAGIELLONIAN UNIVERSITY, POLAND

Agnieszka Hess

ORCID: 0000-0002-4799-9216

JAGIELLONIAN UNIVERSITY, POLAND

DOI: 10.19195/1899-5101.12.2(23).8

\begin{abstract}
In this paper fundamental information concerning the designing and conducting of comparative experiments, as methods which are able to be employed in the field of media studies, will be successively delineated. On the basis of the large-scale online experiment conducted in 15 countries in 2017, the assessment of the populist message impact as well as methodological challenges to such a project will be presented. We discuss challenges and lessons learnt from this type of research design.
\end{abstract}

KEYWORDS: populism, populist communication, comparative experiment.

\section{INTRODUCTION}

Populism as a phenomenon that is hard to assess and poses a substantial challenge to scientific operationalization has been depicted by many scholars. In recent years, however, this niche in scholarship has been subsequently filled with empirical evidence from the field. The aim of the article is to present remarks coming from the research conducted within the joint international comparative research: COST

* An extended version of the text was published in Polish in A. Szymańska, M. Lisowska-Magdziarz, \& A. Hess (Eds.). (2018). Metody badań medioznawczych i ich zastosowanie. Kraków: Wydawnictwo IDMiKS. 
IS1308 Action "Populist Political Communication in Europe: Comprehending the Challenge of Mediated Political Populism for Democratic Politics" (2013-2018). ${ }^{1}$

One of the many advantages of that extensive research framework was usage of a social experiment as a method in assessing the influence the populist message has on European citizens. As presented in the course of the article, this endeavor should be seen not only as a way to put under scrutiny the effects of populism present in the public sphere but also, as more evidence of utility of a social experiment in the field of media studies. On the other hand, the main difficulty in running social experiments is that it occurs in the common space of many individuals, where a multitude of often complex social relations overlap. It also affects the processes of social communication, including communication in the media.

\section{GENERAL CHARACTERISTICS OF A SOCIAL EXPERIMENT}

In general, experiments are an essential and effective manner of verification based on the experience of previously accepted suppositions (hypotheses), however, as a research method they have numerous challenges. What is key to this, is the adjective "social" linked with transferring an experiment from a sterile, both literally and figuratively, laboratory. An experiment is a method which was employed in natural science as evolving in the 17th century. Subsequently, this experiment was transferred to psychological research in the 1960s (Greenberg \& Shroder, 2004, p. 15), and has been employed in media research, where it is highly valued due to the possibility of isolating and verifying the influence of specific elements of political announcements. This experiment, in the hypothetical-deductive sense, serves as a falsification or critique of the hypothesis of what Popper (1959) recognized as the most important method of science (empirical). It is based on "submitting theses, deriving deductive conclusions from them, regarding the subject of the results projected by the experiments, and then confronting them with the factual experimental results" (Grobler, 2006, pp. 63-64).

In social research an experiment should take into consideration observations as well as diagnostic surveys, that is, two other empirical methods, which are popular and deeply rooted in this type of academic search. Observation is every type of planned procedure for gathering empirical data, whereas a diagnostic survey is the manner of amassing knowledge about the structural and functional attributes, as well as the dynamics of social phenomena, opinions, and viewpoints of selected groups - collectivities, and the escalation and directions of the developments of specific phenomena (Grobler, 2006, p. 65). We obtain indirect proof in surveys i.e., the opinions of those being polled on the subject of the influence of media sources of information.

\footnotetext{
${ }^{1}$ For more information about the project and the research team please check: https://www.ntnu. edu/populistcommunication/populist-political-communication-in-europe (accessed March 20, 2019).
} 
Against this background, the experiment appears as a type of observation, be it however demanding of the researcher an offensive approach regarding the reality being researched (Boruch, 1994). In other words, mobilizing to a scientific provocation to such an extent, that it serves to reproduce the amassing and analysis of data, as it is dependent on the deliberate influence of the researcher on natural processes and states. A more specific definition of this experimental procedure understands it as: "the recurring procedure dependent upon a planned change by the researcher of certain factors in a researched situation, by a simultaneous control of other factors, undertaken with the goal of obtaining via observation responses to the question as to the effects of this change" (Sułek, 1979, p. 13; translations from Polish of all cited fragments were done by the Authors).

As opposed to other empirical research, the social experiment values, above all, a planned and active participation of the researcher. It should be mentioned here that in the social sciences the label of "experiment" also describes other types of activity, which, similar to social experiments, may possess an innovative character, do not always have scientific recognition as their goal. Examples of this would be undertakings of a practical character (goal), social reforms accomplished through the use of ground-breaking methods on a local or international scale (Greenberg \& Shroder, 2004). These activities, which are teleological in their very nature, are not dependent upon a rigorous internal control, they are considered to be appropriate, to the extent that they bring about the desired change, for example, solving such social problems as unemployment in a given region.

Another, not thoroughly precise use of the term "experiment" is present in the instance of post factum activities, when researchers conduct an analysis of the causes and effects of those social transformations, which were not "provoked" by themselves, but occurred simultaneously, idiopathically, and had such a clear process, that they could be delineated. A model example of such a "natural experiment" would be research of the social effects of changes in the demographic structure of society or of internal migrations caused by natural disasters (Sułek, 1979, pp. 1617). In the first as well as in the second instance, activities which may be labeled as experimental, are not subject to internal procedural control, that is, they cannot be, or deliberately are not subject to verification as to their scientific character.

\section{KEY CONCEPTS, FACTORS AND CHALLENGES}

There is an entire series of other essential notions linked with the concept of social experiment, such as the causal link, dependent and independent change, stimulus, the canon of a single difference, the experimental diagram (an experimental and control group), and verification in an experiment. As Francuz and Mackiewicz write: "The quest for constancy is the primary goal of scientific research. The creation of scientific laws is exactly the search for permanent links between varied attributes of the objects being researched" (2007, p. 26). Over the course of an experiment, there 
is a procedure, in which the researcher manipulates at least one variable, conducts research on another variable, and attempts to control or limit the influence of the remaining variables. Depending on whether these variables compose the cause or also the effect, we may divide them into being independent - being the cause clarifying, or dependent, that is clarified. As was indicated earlier, over the course of social experiments, including those conducted in the fields of communication or of media studies, attempts are being made to clarify social phenomena, and their accompanying (often complicated) causes.

The space of social communication is a multi-dimensional milieu, in which individual factors function (for example communicative competence, open or underlying motivations, linked with individual differences), as well as the appearance of a series of individual or compound groups of communicators, (not only do individuals communicate, but also collective entities, for instance editorial staff). It also occurs that the same statement takes on varied forms, and filters through art a different time, by means of various channels (direct communication, the traditional media, or via the Internet, which constitutes an example of conflicting variables linked with an experimental situation). Therefore, it is exceptionally difficult for researchers of the processes of social communication to arrive at an experimental situation, in which they control or are able to limit the influence of the remaining independent variables.

The aforementioned elements influencing the behavior of those being researched, and at the same time not subjugating themselves to the control of the researcher, belong to the group of independent conflicting variables. Over the course of a social experiment, they should be considered to be factors which may disrupt the process of the experiment and change the results. Similarly, with regards to the experiment itself, both its design and course may also have an impact on the results (and interfere with them) which is something the researcher should also take into consideration, while adding their own diligence in the realization of the experiment.

Equally essential for the research activity in question, is indicating the direct possible causes of specific behavior, that is, of independent essential variables, including both the primary and peripheral one. Those variables, which the researcher has "under control" establish their existence and amount of influence on the behavior which is to be researched. They fulfill a function of causes or stimuli influencing the changes of behavior, which influence the coinciding changes in behavior. The second group of variables include those explications, for instance behavior, which appear under the influence of the aforementioned (controlled or uncontrolled) factors. These are dependent variables. The researcher measures them during the experiment and they constitute the effects appearing under the influence of the specific type of stimuli employed by the researcher.

The canon of one difference (method of one difference) is the next category of essential empirical research which should be recognized. This is a term proposed by the English philosopher John Stuart Mill in 1843. He was the first to describe 
a situation in a systematic manner, when some types of processes were appearing together with a specific phenomenon, however they did not appear at all, when the given phenomenon did not materialize (Mill, 2009). One could then conclude that these processes - being the only difference dividing two mentioned situations - play a causal role of the phenomenon being researched. That is why the goal of a researcher designing an experiment is to create such conditions, in which the expository variable, employed to evoke a specific effect, constitutes the only discriminative variable. It is worth remembering here that in experimental practice it is possible (and is often performed) to conduct research on the influence of many expository variables on a single expository variable. However, it should be remembered that the more expository variables there are, the more difficult it is to evaluate the influence of specific variables on designated behavior.

As far as an experimental design is concerned - that is, the manner in which an experiment is conducted, the character of the group of participants taking part in the experiment, as well as the procedure for using stimuli regarding them, are also important. This is linked with the concept of the experimental and the control group. The experimental group is composed of people subject to the influence of an independent variable (stimulus). The control group however, includes research of the same characteristics as the experimental group, dependent upon procedures identical to those found in the experimental group. The participants of the control group, however, are not subject to the influence of independent variables, the influence of which is researched (in this manner, the canon of the only difference becomes the research model). There may be more than one experimental and one control group in an experiment, it depends on which pattern/experimental plan is employed. In a later part of this article, the course of research in eight research groups (six experimental and two control groups) will be presented. This is an example of an experiment carried out according to the multi-causal plan.

In order to discuss scientific categories in experimental research, this research has to be subject to a restrictive procedure of internal control. This deals with several aspects of the organization and the process, namely: checking the internal accuracy, that is, assuring that nothing more than the stimulus employed influences the result (dependent variable). In order to obtain internal accuracy, all peripheral (disruptive) variables are examined. It is also of key importance to designate the research subject to groups randomly, as well as guaranteeing that in a situation in which these groups participate, differ only according to the value of the independent variables.

The second essential element of internal accuracy control is establishing the level of confidence (value $p$ ). The indicate value includes the number computed with the help of statistical techniques, stating what is the probability that the results of an experiment are due to chance, and not the result of the activity of an independent variable or variables. The results are considered to be statistically significant, when $p<0.05$. 
Internal accuracy is considered to be an additional dimension of control in the experiment, that is, generally speaking, the range of results and their usefulness, understood to be a level, at which research results may be generalized for other situations or groups. The researcher should provide for situational realism, which means such a scenario, where experimental situations will be similar to those encountered in social reality. It is also worthwhile to maintain an awareness of the influence of factors which are beyond the researcher's control.

Random factors which often skew the results of an experiment include natural changes within the research group (the evolution of an institution), the execution of a pretest or some of the participants knowing the results of a pretest, the principle of regression, a change of the measurement method during the experiment, and differences in the selection of participants in control and experimental groups (for more about the sources of internal inaccuracy, please check Cook \& Campbell, 1979).

As was previously mentioned, a social experiment is a scientific manner of acquiring knowledge concerning phenomena occurring in human collectivities, which is conducted in order to verify a hypothesis. Not every hypothesis may be verified through the aid of an experiment, we would like to remind the reader: It is a planned activity and requires the activity and intervention of a researcher. This also occurs in the social sciences, including media sciences. A researcher who undertakes preparations to make an experimental diagram, must answer three essential questions: (1) What do we want to find out? (2) How accurate do our results have to be? (3) What group should these results and this knowledge concern?

The design of research proceedings consists of five stages. The first stage consists of an identification of facts requiring a clarification (formulating a research problem), in order to propose one or many hypotheses (which are possible clarifications for the phenomena researched). Then what is important is the presentation of a deduction of previously proposed hypotheses of empirical consequences, that is of individual sentences about facts, that is, of the so-called observational opinions. These are subject to empirical tests, which happen over the course of the experiment and/ or observation. The research proceedings become a closed analysis of selected data.

Conducting an experiment is usually hindered by that fact that all hypotheses may be "explained" by such observational opinions, which may become an object of manipulation by the experimenter. In other words, it is not always possible to design a methodologically proper experiment, which would provide a response to the previously posed research questions.

A factor which excludes the possibility of conducting an experiment is at times the very subject of the research. An illustration of this would be a research undertaking which had to verify for example, how frequent would the watching of films with scenes of explicit violence have to be in order to influence the percentage of murders committed by minors. After all, one may not, even for research purposes, shock young adults with images of murders, all the more so, as there exist presumptions that this would evoke aggressive behavior among them. Generally, social 
experiments involve human creations as well as human beings, hence they have a lot of controversies and questions of an ethical nature. It was no different with the famous "prison experiment" known from psychological literature from 1971 (Stanford prison experiment - SPE) However, during the second (1961 and 1963) Stanley Milgram answered the question as to the cause of blind obedience to those in authority and their orders, which led people to commit genocide for instance, in concentration camps, during World War II (that is, the Milgram experiment).

Other examples of ethical problems in experimental research are research of children, the confidentiality of information obtained over the course of the research, and provoking situations which could evoke constant and negative emotional states amongst those people being researched. Currently, the ethics of experimental research dictate, amongst others, that full information about the course of the research be supplied to those taking part, that a conscious agreement be obtained from all participants, that none of them would suffer any injury or discomfort, etc. An exception would be a situation in which the only way to conduct the research would be to misinform the participants. In such a situation, however, it would be necessary to conduct a session after the experiment, clarifying the situation (so-called de-masking).

In addition to the ethical questions described in the research above, a lot of difficulty is linked with factors disturbing the precision of the conclusions. A reference should be made here to research conducted in the so-called "natural environment" of a delineated group, a specific example is the Internet, which is difficult to control and even difficult to imagine (and make the appropriate assumptions) of variables disrupting the experiment. In such instances, severing the continuity of the time and place of the experiment increases the risk of disruptions appearing. A participant in an online experiment may be subject to a stimulus from his immediate surroundings, which is of course inaccessible for the researcher, or even the type of media equipment used (tablet, telephone, desktop computer) and linked to this, a simultaneously accessible source of information, which is difficult to limit, etc. In as much as the research cannot be conducted in conditions which are under the maximum control of the researcher (a place previously prepared by the researcher, where disruptive factors are limited to a minimum) the conducting of an online experiment turns out to be one of the most difficult methodological tasks, due to the appearance of many independent, disruptive variables.

\section{EXPERIMENT ON POPULIST POLITICAL COMMUNICATION ONLINE}

The main task of the COST Action IS1308 action entitled "Populist Political Communication in Europe: Comprehending the Challenge of Mediated Political Populism for Democratic Politics" was to propose a functional definition of populism, indicating the political actors (populists) recognizing and characterizing populist strategy employed in political communication, analyzing the content of the media 
and the position of journalists regarding populism, as well as evaluating the influence of the populist statements on the societies of the European Union.

The field of research, which is populist communication, has been widely defined as an area in which there are three types of communicators: that is, of political actors, the media, and citizens. Following this approach, populism is analyzed as a strategy or style of communication used by these three types of participants, where the content includes three main elements: a positive evaluation of the people, and a negative attitude towards elites (anti-elitism), and others (exclusion). Depending on the combination of these elements we recognized, following Jagers and Walgrave's (2007) concept, four main types of populism: (1) empty populism (includes only references and appeals to the people), (2) anti-elitist populism (includes references and appeals to the people and anti-elitism), (3) excluding populism (including only references and appeals to the people and exclusion of out-groups), and (4) complete populism (including references and appeals to the people as well as anti-elitism, and exclusion of out-groups).

The Research in Action project was conducted using a mixed research plan, in which parallel research methods (interviews with politicians and journalists; media content analysis, and social experiment) were employed. The social experiment was conducted on a group of Internet users, from 15 different countries (mostly from the European Union), ${ }^{2}$ in 2017, and was a delineation of the influence of these four types of populist messages to the citizens of these countries (Hameleers et al., 2018).

The goal was so formulated, as to require the conducting of research which on the one hand clarified these processes on an individual level (the influence of the populist message on an individual) and at the same time this enabled an extrapolation (transfer, generalization) of individual results to the level of the collectivity. It was necessary to link the attributes of the diagnostic poll (representative research for a given population) with the experimental diagram, according to which certain recipients were sent (which could be considered a stimulus) each of the four types of populist political messages (points 1-4).

Starting with the supposition that a cognitively worthwhile experiment demands an elaborate theory, creative manipulation, and good tools of measurement, in the theoretical area, the party of researchers proposed an expanded model postulating a clarification of the cause-effect processes in populist communication on an individual level. Potential direct and indirect causes (independent and expository variables) as well as the reaction of recipients of populist political messages dealing with the sphere of attitudes, and behavior (dependent and expository variables) were taken into consideration.

2 The Polish part of the study (online experiment) was co-funded by the National Science Center, Poland, research grant: 2015/18/M/HS5/00080 and the resources of the Faculty of Management and Social Communication of the Jagiellonian University. 
Indirect causes essential in the process of influencing the individual and society via the populist political message were the predisposition of individuals and in a wider socio-political context. On an individual level, essential significance (influence) was assigned to demographic variables - sex, age, level of education, as well as psychological factors - feelings of being threatened, of belonging to a group (community) and consumption models from the media. With regards to the sociopolitical context, the economic situation of each country was taken into consideration, as well as the migration context, the general level of confidence in institutions, and finally the election results of the populist parties. Such an elaborate theoretical model demanded the use of a somewhat complicated experimental diagram/design, exceeding the often employed research of one (experimental) or two groups of experimental and control.

In all 15 countries the design of the experiment was identical: the same stimulus was employed (an independent and expository variable) as well as eight groups of participants. The division of the participants was a result of the fact that the stimulus itself had four variations (points 1-4), whereby these four types of populism were collocated in six variants, which give six experimental groups. The remaining two groups had however, a control function. The stimulus in each instance was supposed to be fictional, but giving the impression of a current piece of news on a well-known Internet site, furnished with a picture. It was shown for 20 seconds. After that time expired, there was a measurement of the influence of the stimulus, that is, research done through a questionnaire.

Table 1. Overview of the experimental design

\begin{tabular}{|c|c|c|c|c|}
\hline \multicolumn{2}{|c|}{} & \multicolumn{2}{|c|}{ Blame on political elite } \\
\hline \multirow{2}{*}{$\begin{array}{c}\text { People } \\
\text { centrism }\end{array}$} & & $\begin{array}{c}\text { Blame on } \\
\text { outgroup }\end{array}$ & No & Yes \\
\hline \multirow{2}{*}{$\begin{array}{c}\text { Yes } \\
\text { (populism) }\end{array}$} & No & $\begin{array}{c}\text { (1) Empty } \\
\text { populism }\end{array}$ & $\begin{array}{c}\text { (2) Anti political } \\
\text { elite populism }\end{array}$ \\
\cline { 3 - 5 } & immigrants & $\begin{array}{c}\text { (3) Right-wing } \\
\text { exclusionist populism }\end{array}$ & $\begin{array}{c}\text { (4) Right-wing } \\
\text { complete populism }\end{array}$ \\
\cline { 3 - 5 } & On the rich & $\begin{array}{c}\text { (5) Left-wing } \\
\text { exclusionist populism }\end{array}$ & $\begin{array}{c}\text { (6) Left-wing } \\
\text { complete populism }\end{array}$ \\
\hline & $\begin{array}{c}\text { No } \\
\text { (no populism) }\end{array}$ & No & $\begin{array}{c}\text { (7) Control 1: } \\
\text { factual story }\end{array}$ & $\begin{array}{c}\text { (8) Control 2: } \\
\text { anti-political elite }\end{array}$ \\
\hline
\end{tabular}

Source: COST Action IS1308.

The subject of the political message included a prediction of the future fall of household purchasing power in the 15 countries presented by a fictional foundation called Future Now, which explained the causes and attributed the responsibility for the predicted crisis to various groups of those "guilty." The text was accompanied by 
an illustration in all cases. A total sample of 17,597 was collected in 2017 and included Austria $(N=1,138)$, France $(N=1,192)$, Germany $(N=991)$, Greece $(N=1,116)$, Ireland $(N=951)$, Israel $(N=1,016)$, Italy $(N=1,056)$, the Netherlands $(N=934)$, Poland $(N=1,368)$, Portugal $(N=1,048)$, Spain $(N=1,010)$, Sweden $(N=1,063)$, Switzerland $(N=1,134)$, United Kingdom $(N=1,103)$, Norway $(N=1,009)$, and Romania $(N=1,468)$. National quota were applied for gender, age, and education based on official national data (Hameleers et al., 2018). The final dataset included the total number cut down by 2,185 inattentive respondents in order to uplift the quality of the data (Hameleers et al., 2018, p. 524). The sample included a diverse group of European citizens, with regard to age $(M=45.91, S D=15.19)$, gender $(M=0.50$, $S D=0.50)$, education $(M=2.25, S D=0.70)$. The important components were also the scope of political interest and ideological profiles of respondents.

In order to verify a series of hypotheses, a large amount of data was collected using an extensive tool in the form of a standardized questionnaire containing 31 questions. Thanks to this, the leading experiment determined the demographic profile of the respondents, the sources of political information media, attitude towards politics and society, and level of trust, attitude to elites and immigrants. To these, manipulation check questions were added, in order to later help in the data cleaning process.

The hypotheses verified in the course of the experiment concerned the course of populist communication and the impact of such messages placed online on blaming (attributing blame) to external groups of "ordinary citizens" to groups of "enemies," which included political and economic elites (politicians, the rich) and immigrants. Other dependent variables tested were populist attitudes, voter intention, and stereotypes about the out-groups.

To assess the impact of independent variables, taking into account other potentially interfering variables, several statistical data analysis methods were used, including multi-level modeling, allowing simultaneous analysis at multiple levels of aggregation, and the Stata software package was used for the analysis itself. It is worth noting that the experiment itself could be used in a methodological way, as it provided relevant information on this method and its application in international comparative research.

Thus, we are dealing with a test and methodological experiment, as the research method becomes the subject of the experiment conducted in order to study and improve existing and construct new cognitive techniques. Changed elements of the research procedure are introduced with the intention of determining their impact on the obtained results, and methodological innovations (international character as a way of ensuring repeatability) are checked by their application. It will be necessary to repeat the experiment with simultaneous differentiation of theoretically irrelevant aspects of the stimulus (channel - Internet, source - press).

The use of the Internet allows for a near-natural situation, and a heterogeneous sample of people (from the point of view of the key socio-demographic variables) 
from each country allowed for testing multiple potential moderating effects. As a result, the impact of one-time exposure, familiarization with the populist media message forecasting another economic crisis was confirmed. It projected an attitude of blaming primarily the rich part of society, followed by immigrants and, to a lesser extent, political elites. Key findings suggest that single elements of populist message "on their own" do not significantly increase or weaken political engagement, but it is a specific combination of in- and out-group elements that makes populist cues effective. At the same time, the research showed that populist messages affected blaming attribution, that is, the extent to which people perceive different in- or outgroups as responsible for a negative situation. Stereotypes about these groups were influenced to a lesser extent (Corbu et al., 2019, forthcoming). In the course of analysis the effects of exposure to a populist message on citizens' political attitudes and voter intentions were also tested and explained (Andreadis et al., 2019, forthcoming). In most of the countries in this experiment, populist attitudes of citizens were not influenced considerably by populist communication cues or their interactions. As far as voting intentions for populist parties are concerned, the anti-immigrant cue has the strongest impact on voting for right-wing populist parties (but yet only in 5 of the 15 countries - Greece, Norway, Romania, Sweden, and Switzerland). As authors conclude on the basis of the experiment: "Contrary to the voting behavior or intensions that can be driven by short-term factors or singular, non-recurring events, people's attitudes are harder to change, which seems to be the result of a long-term process of (political) socialization" (Andreadis et al., 2019, p. 228).

\section{DISCUSSION AND CONCLUSION}

As mentioned, the comparative experiment is seen as a suitable method in projects in which testing media effects in various contexts is the main goal. As illustrated by the example of the COST research project on populist communication on the Internet and its impact on citizens, it may concern not only significant and central areas in public discourse, but above all provide explanations at the small group level, also in an international context, and serve comparative purposes. Although there are a number of factors that influence the inefficiency of internal experiments, as shown in this complex example, their awareness and the application of corrective or error-reducing strategies can effectively limit the influence of non-experimental factors on the explained variable.

The team, whose undoubted success was to carry out such a complex research project, in its publications indicates a number of important limitations (for results and details see Hameleers et al., 2018, Bos et al., 2019, Corbu et al., 2019, Andreadis et al., 2019).

The biggest methodological challenges refer to the cross-country, comparative character of the experiment. In the course of conceptualization and operationalization almost all of the key elements of research design presented challenges. It refers to 
the topic itself (populism), choice of the stimuli layout but also data collection (questionnaire). The proposed definition of the populist that focuses on its communicative aspects and an interplay between several actors (politicians, citizens and media) should be seen as a clarifying endeavor that overcame existing discrepancies in its understanding in particular countries. The importance of Internet-based political communication, the scope, as well as the timeline and budget of the project influenced the choice of an online experiment scenario. In the course of the preparations, one of the biggest challenges were (and still are) structural differences between EU member states, to name the most important: broadband Internet access rate (ranging from approx. $60 \%$ up to $99 \%$ ), patterns of media consumption, demographic and educational structure of societies as well as the course and results of the 2008 economic crisis in particular parts of Europe. An important element that also differentiated cases (countries) were the list of the "outgroup" to be blamed and contrasted with the pure people (ranging from refugees, immigrants, migrants, to rich/wealthy and political elites, both domestic and foreign). All that, as well as the necessity of translation to native languages of the stimuli and the questionnaire implied quite a general content of the "populist message" that was presented in the stimuli and later tested.

As in any experiment, the choice of the stimuli represented a limitation in itself. Additionally, in comparative experiments, the choice of the topic and general construction of the stimuli raise great challenges. In this particular case, the choice of topic, the purchase power, was subject to debates about not only relevance, but also credibility in various countries. Additionally, the choice of wording of the various frames of the neutral story was very much influenced by various country-related specificities.

Although the results supported some of the hypotheses of the effects of shortexposure to populist message impact on various key variables, conducting experimental research in 15 countries and collective data analysis is associated with difficulties in explaining differences observed between countries. It is in line with scholarship that suggests that phenomena of populism and its impact are deeply context-dependent.

It is suggested that future research should aim to develop theoretical ideas that allow for testing the interactions between levels in the multilevel model, that is, giving the opportunity to explain the differences visible in individual countries.

\section{ACKNOWLEDGMENTS}

The work is funded by the National Science Center, Poland, research grant no. 2015/18/M/HS5/00080. 


\section{REFERENCES}

Aalberg T., Esser F., Reinemann C., Strömbäck J., \& de Vreese. C. (Eds.). (2017). Populist political communication in Europe. New York: Routledge.

Andreadis, I., Cremonesi, C., Kartsounidou, E., Kasprowicz, D., \& Hess, A. (2019). Attitudinal and behavioral responses to populist communication: The impact of populist message elements on populist attitudes and voting intentions. In C. Reinemann, J. Stanyer, T. Aalberg, F. Esser, \& C. de Vreese (Eds.), Communicating populism: Comparing actor perceptions, media coverage, and effects on citizens in Europe (pp. 207-232). New York: Routledge.

Boruch, R. (1994). Randomized experiments for planning and evaluation. Thousand Oaks: SAGE Publications.

Bos, L., Schemmer, C., Corbu, N., Hameleers, M., Andreadis, I., Schulz, A., Schmuck, D., et al. (2019, forthcoming). The effects of populism as a social identity frame on persuasion and mobilization: Evidence from a 15-country experiment. European Journal of Political Research.

Cook, T., \& Campbell, T. (1979). Quasi-experimentation: Design and analysis issues for field settings. Chicago: Rand McNelly.

Corbu, N., Bos, L., Schemer, C., Schulz, A., Matthes, J., de Vreese, C.H., Aalberg, T., \& Suiter, J. (2019). Cognitive responses to populist communication: The impact of populist message elements on blame attribution and stereotyping. In C. Reinemann, J. Stanyer, T. Aalberg, F. Esser, \& C. de Vreese (Eds.), Communicating populism: Comparing actor perceptions, media coverage, and effects on citizens in Europe (pp. 183-206). New York: Routledge.

Francuz, P., \& Mackiewicz, T. (2007). Liczby nie wiedza, skąd pochodzą. Przewodnik po metodologii i statystyce nie tylko dla psychologów [Numbers do not know where they come from. A methodology and statistics guide not only for psychologists]. Lublin: Wydawnictwo KUL.

Greenberg, D., \& Shroder, M. (2004). The digest of social experiment (3rd ed.). Washington, DC: The Urban Institute Press.

Grobler, A. (2006). Metodologia nauk [Methodology of sciences]. Kraków: Auerus/Znak.

Hameleers, M., Bos, L., Fawzi, N., Reinemann, C., Andreadis, I., Corbu, N., Schemer, C., et al. (2018). Start spreading the news: A comparative experiment on the effects of populist communication on political participation in 16 European countries. International Journal of Press/Politics, 23(4), $517-538$.

Jagers, J., \& Walgrave, S. (2007). Populism as political communication style: An empirical study of political parties' discourse in Belgium. European Journal of Political Research, 46(3), 319-345.

Mill, J. S. (2009). The system of logic. Retrieved December 20, 2018, from https://www.gutenberg.org/ files/27942/27942-pdf.pdf.

Popper, K. (1959). The logic of scientific discovery. London: Hutchinson.

Sułek, A. (1979). Eksperyment w badaniach społecznych [Experiment in social studies]. Warszawa: PWN. 